\title{
JOURNAL OF ANIMAL PRODUCTION ADYANCES
}

\section{Tissue Disposition and Withdrawal Time of Fosfomycin in Swines after Oral and Intramuscular Administration}

Pérez D. S., Soraci A. L. and Tapia M. O.

J Anim Prod Adv 2013, 3(4): 107-119

DOI: 10.5455/japa.20130407054809

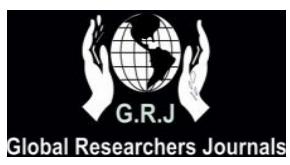




\title{
Tissue Disposition and Withdrawal Time of
}

\section{Fosfomycin in Swines after Oral and Intramuscular}

\section{Administration}

\author{
${ }^{* 1,2}$ Pérez D. S., ${ }^{1,2}$ Soraci A. L. and ${ }^{1,2}$ Tapia M. O. \\ ${ }^{1}$ Laboratorio de Toxicología, Centro de Investigación Veterinaria de Tandil, Departamento de Fisiopatología, Facultad de Ciencias. \\ Veterinarias, Universidad Nacional del Centro de la Provincia de Buenos Aires, Tandil, Buenos Aires, Argentina. \\ ${ }^{2}$ Consejo Nacional de Investigaciones Científicas y Técnicas (CONICET), Buenos Aires, Argentina.
}

\begin{abstract}
A HPLC-MS/MS method, which was suitable to be used in withdrawal time studies, was validated for the determination of fosfomycin in swine muscle, liver, kidney and skin-fat. Therefore, the withdrawal time of fosfomycin in swines, considering a MRL of $0.5 \mu \mathrm{g} / \mathrm{mL}$ was studied. Forty-eight pigs were assigned to two groups; in group one, fosfomycin was orally administered daily with $30 \mathrm{mg} \mathrm{kg}$ bw and to the other group a dose of $15 \mathrm{mgkg}$ bw of the antibiotic was intramuscularly administered. Pigs were slaughtered 24, 48, 72 and 96 hours later of oral treatment withdrawn and post intramuscular treatment. The longer WDT was 2.95 days for the PO administration and 1.73 days for the IM administration; therefore, WDTs of 3 days and 2 days, respectively, could be assigned as a precautionary principle for public health, without a significant economic impact for the swine producer.
\end{abstract}

Keywords: HPLC MS-MS, fosfomycin, swine tissues, maximum residues limit, withdrawal time.

\footnotetext{
* Corresponding author: Laboratorio de Toxicología, Centro de Investigación Veterinaria de Tandil, Departamento de Fisiopatología, Facultad de Ciencias Received on: 13 Feb 2013

Revised on: 28 Mar 2013

Accepted on: 07 Apr 2013

Online Published on: 28 Apr 2013
} 


\section{TISSUE DISPOSITION AND WITHDRAWAL TIME OF FOSFOMYCIN IN ...}

\section{Introduction}

Fosfomycin (cis-1, 2-epoxyphosphonic acid) (Figure 1) is a broad-spectrum bactericidal antibiotic, not structurally related to other classes of antimicrobial agents. It acts inside the bacterial cytoplasm (Popovic et al., 2009) and its mechanism of action is based in the inhibition of cell wall and early murein/peptidoglycan synthesis in proliferating bacteria (Kahan et al., 1974). Fosfomycin inhibits an initial peptidoglycan synthesis step, triggered by uridine diphosphate $\mathrm{N}$ acetyl-glucosamine-enol-pyruvyl-transferase and its co-enzyme phosphonole-pyruvate (Kahan et al., 1974; Lin, 1976; Popovic et al., 2009). It has bactericidal activity against Gram positive and Gram negative bacteria (Gobernado, 2003). Therefore, when compared with other antibiotics, the in vitro fosfomycin activity has a broader spectrum of action than penicillins and semisynthetic cephalosporins (Mata et al., 1977). On the other hand, it appears to be little cross resistance with other antimicrobial agents, possibly due to its chemical structure and action site are different from other agents (Gobernado, 2003; Reeves, 1994).

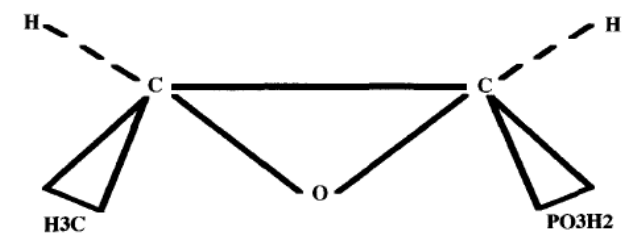

Fig. 1: Chemical structure of fosfomycin.

The use of fosfomycin in animals and humans has been suggested due to its low toxicity and potential efficacy (Gallego et al., 1974). It is well tolerated, with a low incidence of adverse events and rapid bactericidal effect (Patel, 1997). Fosfomycin forms salts easily due to its acidic nature. Orally, it is used in its calcium salt form (Figure 2), and intravenously and intramuscularly, as the more water-soluble disodium salt (Figure 3). Fosfomycin-tromethamine salt is highly hydrosoluble and has a good oral bioavailability in humans (Patel et al., 1997; Borsa et al., 1988; Popovic et al., 2009). Fosfomycin is also widely used in animal production, especially in poultry and pig production, due to its rapid effect, good tolerance and absence of side effects (Aramayona et al., 1997; Carramiñana et al, 2004). Particularly in swine's, this antibiotic is used for the treatment of infectious diseases caused by Haemophilus parasuis, Streptococcus suis, Pasteurella multocida, Bordetella bronchiseptica, Staphylococcus hyicus and $E$. coli), associated with stress and different viral infections (Martineau, 1997).

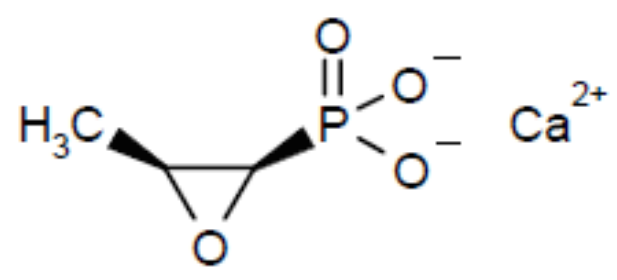

Fig. 2: Chemical structure of calcium fosfomycin.

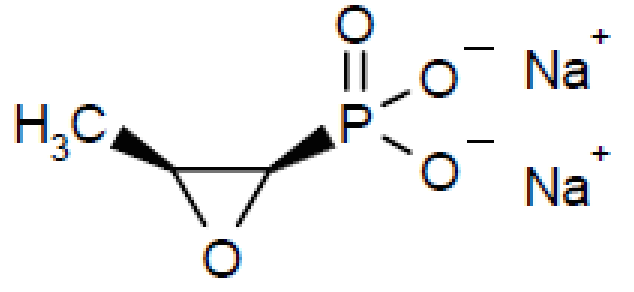

Fig. 3: Chemical structure of disodium fosfomycin.

Fosfomycin pharmacokinetic has been extensively studied in humans (Dámaso et al., 1990; Falagas et al., 2008; Gallego et al., 1971; Grassi, 1990; Kirby, 1977; Mensa et al., 1994; Segre et al., 1987; Simon et al., 1987; Vargas et al 1987), broiler chickens (Aramayona et al., 1997, Soraci et al., 2011), rabbits (Fernández Lastra et al., 1986; 1987), cows (Sumano et al., 2007), horses (Zozaya et al., 2008), dogs (Gutierrez et al., 2008) and pigs (Soraci et al, 2010; Pérez et al., 2013). Likewise, different analytical methods for determination of fosfomycin in biological matrices have been described in the literature (Pianetti et al., 1997; Dios-Viéitez et al., 1996; Yu-Ling $\mathrm{Hu}$ et al., 1999; Hernandez et al., 2001; Loste et al., 2002; Tzanavaras et al., 2002; Petsch et al., 2005). Most of them are time consuming and include a derivatization step for the analysis. Currently, HPLC MS/MS is the method of choice for xenobiotics residues determination. For fosfomycin, this method has the advantage that derivatization is not needed, becoming a much easier, less time consuming, and highly specific methodology at the same time ( $\mathrm{Li} \mathrm{Li}$ et al, 2007; 
Dieguez et al, 2011; Soraci et al, 2011; Pérez et al., 2011). However, when working in HPLC-MS/MS with biological matrices, care must be taken to avoid interferences which are prone to alter signal by ion suppression/enhancement mechanisms.

The administration of veterinary drugs to foodproducing animals without an adequate withdrawal time (WDT) may lead to violative concentrations of residues in foods intended for human consumption. These residues represent a risk to public health, including stimulation of bacterial resistance, alterations on intestinal microflora and hypersensitivity reactions. Therefore, to ensure the delivery of safe animal products to consumers, the withdrawal time of drugs must be respected. Thus, with the aim of minimizing the risk for human health represented by residues in food products, MRLs for many drugs have been established by regulatory agencies of different countries. However, the European Agency for the Evaluation of Medicinal Products (EMEA) and the European Commission have not established the MRLs for fosfomycin. The Japan Food Chemical Research Foundation has established MRLs of $0.5 \mu \mathrm{g} / \mathrm{mL}$ for cattle muscle, liver, kidney and fat and a MRL of $0.05 \mu \mathrm{g} / \mathrm{mL}$ for milk. No MRLs has been established for pig tissues by any regulatory agencies.

In the extra vascular administration of a drug, the pharmaceutical formulation may condition the rate of absorption and, consequently, the final elimination phase. According to this, a formulation may require a longer WDT when the drug is slowly depleted from tissues. Otherwise, a shorter WDT can be used when faster depletion is adequately proven. Consequently, the administration of one or another formulation of the same drug leads to violative concentrations of residues if individual WDTs are not considered. Although there are different pharmaceutical formulations of fosfomycin, only the calcium salt is used in pigs for oral administration, while the more water-soluble disodium salt is used intramuscularly (Soraci et al., 2010; 2011). Nevertheless, and considering that fosfomycin is an antibiotic widely used for pig production, WDT in swine tissues has not been investigated.
On a previous work we have studied fosfomycin residual concentrations in chicken muscle, liver and kidney by HPLC MS/MS (Pérez et al., 2011). In the present study, this simple, rapid and highly selective HPLC-MS/MS method was validated to determine fosfomycin in swine tissues (muscle, liver, kidney and skin-fat). This study was also aimed to determine WDTs of calcium fosfomycin in pigs after an oral treatment and of disodium fosfomycin after intramuscular administration. For this purpose, the only known fosfomycin MRL $(0.5 \mu \mathrm{g} / \mathrm{mL})$, established by Japan, was considered (Japan Food Chemical Research Foundation).

\section{Materials and Methods}

This work was performed at the Laboratory of Toxicology, Veterinary Research Center of Tandil (CIVETAN-CONICET) and the experimental farm of the Faculty of Veterinary Sciences, UNICEN, Tandil, Buenos Aires, Argentina.

\section{Animals}

For method validation, five healthy, 145-150 day-old pigs were used. Animals received an antibiotic-free diet and water ad libitum. After euthanasia, tissue samples were collected. Organs were weighted and 1:2 part of methanol was added. Then, tissues were processed by a hand blender and stored at $-20^{\circ} \mathrm{C}$ until analysis.

For residue analysis and withdrawal time calculation, forty-eight healthy 145-150 day-old pigs, were used. One week before experimentation (acclimation period), no clinical signs of disease were apparent. Food (the ration was formulated according to breed standard requirements) and no medicated water were supplied ad libitum. Experimental animal's conditions were in agreement with the Animal Welfare Guidelines approved by the Bioethics Committee of the Faculty of Veterinary Sciences, UNICEN, Tandil, Argentina and the recommendations of the European Council Directive 2007/43. Pigs were sacrificed under the Animal Welfare Rules of the European Council Directive 93/119/CE 1993.

Pigs were weighed and divided randomly into two experimental groups of twenty four animals (A and B groups). The A group (24 pigs) was treated 


\section{TISSUE DISPOSITION AND WITHDRAWAL TIME OF FOSFOMYCIN IN ...}

individually with $30 \mathrm{mg} / \mathrm{kg}$ bw of calcium fosfomycin (98.9\% of purity; Bedson Laboratory, Pilar, Buenos Aires, Argentina) orally administrated once daily for five consecutive days (every morning, between 7 and 8 a.m.). The drug was weighed, diluted in water and administrated using a plastic gastric catheter to assure the complete ingestion of the dose. For intramuscular assay, (B group, 24 animals), disodium fosfomycin (98.9\% of purity, Bedson Laboratory, Pilar, Argentina) was diluted in sterile water and intramuscularly administered, at $15 \mathrm{mg} / \mathrm{kg}$. bw.

\section{Reagents and chemicals}

Fosfomycin calcium and disodium salts (analytical standard, STD), purchased from Sigma (St. Louis, USA), were used. HPLC grade acetonitrile, isopropanol and methanol were from JT Baker (Deventer, Holland). Ultra purified deionized water was obtained using a water purification devise (Pure Lab UHQ from ELGA [Lane End, UK]). Silica Gel 60 (0.040-0.063 mm.) was from Merck (New Jersey, USA). Stock solution of fosfomycin was prepared by dissolving $10.0 \mathrm{mg}$ of drug in $25 \mathrm{~mL}$ of purified water.

\section{Instruments HPLC MS/MS system}

The HPLC-MS/MS system was from Thermo Electron Corporation (San Jose, CA, USA), consisting of a Finnigan Surveyor auto sampler and a Finnigan Surveyor MS quaternary pump. The detector was a Thermo Quantum Discovery Max triple quadrupole mass spectrometer, equipped with an ESI source. Nitrogen used as nebulizer and sheath gas was obtained through a nitrogen generator from Peak Scientific Ltd. (Inchinnan, Scotland). Data processing was done using Xcalibur software, also from Thermo.

\section{Mass Spectrometer conditions}

The mass spectrometer was operated in negative ionization mode. The tuning parameters were optimized with $10 \mu \mathrm{g} / \mathrm{mL}$ individual aqueous solutions of fosfomycin directly infused in the ion source by means of a syringe pump at $10 \mu \mathrm{l} / \mathrm{min}$, with influence of mobile phase delivered from the LC pump through a $\mathrm{T}$ connection to give the corresponding chromatographic flow rate. The spray voltage was set at $-3800 \mathrm{eV}$, the capillary temperature was $350{ }^{\circ} \mathrm{C}$, and argon $99.99 \%$ purity was used for collision induced dissociation (CID) at $1.6 m$ Torr in the collision cell. Source CID energy was set at $-8 \mathrm{eV}$. Fosfomycin detection and quantification were achieved by single reaction monitoring of transitions $\mathrm{m} / \mathrm{z} 137 \rightarrow 79$ with an optimized collision energy of 25 .

\section{Chromatographic conditions}

Separation was achieved on a Phenomenex CN (cyano) stationary phase, $75 \mathrm{~mm}$ x 4.6 i.d., $5 \mu \mathrm{m}$ column. The mobile phase consisted on acetonitrile:water (20:80), working in isocratic mode, at a flow rate of $100 \mu \mathrm{l} / \mathrm{min}$. The column was maintained at $30{ }^{\circ} \mathrm{C}$, while the samples in the auto sampler were at $10{ }^{\circ} \mathrm{C}$. Sample injection volume was $20 \mu \mathrm{l}$ and chromatographic run time was 10 $\min$.

\section{Standard solutions preparation}

\section{Quality control samples (QC)}

Fosfomycin solutions to fortify drug free tissues before extraction were prepared daily, by diluting adequate volumes of stock solution in water. Fifty $\mu \mathrm{l}$ of each solution were thoroughly mixed with $1 \mathrm{~g}$ of tissue, to obtain effective fosfomycin concentrations of $0.1,0.5$ and $1 \mu \mathrm{g} / \mathrm{mL}$.

\section{Calibration solutions}

Drug free extracts were spiked with $100 \mu \mathrm{l}$ fosfomycin working solution at different levels just before injection into HPLC-MS/MS system, to obtain concentrations corresponding to $100 \%$ extraction over the range of 0.1 to $4 \mu \mathrm{g} / \mathrm{mL}$.

\section{Sample extraction}

One gram of tissue was placed in a glass mortar containing four grams of silica gel and mortared until the sample was completely dispersed into the silica. Columns were assembled in 20-mL syringes, placing a Whatman GF/B filter on the bottom, followed by a dispersion of silica gel with the tissues. Another Whatman GF/B filter was placed above. Columns were pressed with a piston. Each column was placed in a vacuum chamber, where different volumes of solvents were applied to wash and elute the sample. Clean up began with $6 \mathrm{~mL}$ of 
acetonitrile. Pressure was kept constant and leakage was uniform in all columns. Then, $5 \mathrm{~mL}$ of isopropanol were applied. The next step was the addition of $6 \mathrm{~mL}$ of methanol. All the solvents were collected in glass tubes and discarded. Properly labeled clean glass tubes were placed in the vacuum chamber. Nine $\mathrm{mL}$ of methanol-water $(2: 1)$ were added and eluted. The $9 \mathrm{~mL}$-eluate was filtered in syringes containing activated carbon and $1 \mathrm{~mL}$ aliquots were filtered with $0.22 \mu$ nylon filters, placed in vials and analyzed by HPLC MS-MS.

\section{Method validation}

Validation parameters, as well as their acceptance range, were in accordance with international guidelines (U. S. Department of Health and Human Services, FDA, CDER, CVM, 2001; European Commission Decision, 2002).

Quantification was achieved by calculating fosfomycin area as the assay response.

Calibration curves were prepared in quintuplicates, and assayed within one week, in order to assess Linearity. Least square linear regression was used for curve fitting.

QC samples fortified at three levels were processed in triplicates on four separate days, in order to assess Accuracy and Precision of the method. The accuracy was expressed as relative error (RE) and it was required to be $\pm 15 \%$ (except for the limit of detection that can reach up to 20\%). Within-day precision (repeatability) was calculated by the mean coefficient of variation $(\mathrm{CV})$, which was required to be less than $15 \%$ for all concentrations (except for the limit of detection where it can reach up to $20 \%$ ).

Lower limit of quantification (LOQ) was defined as the lowest concentration at which both precision and accuracy were less than or equal to $20 \%$, and it was obtained by analyzing fortified tissues at the lower level of the calibration curve, in 5 replicates on three different days.

Recovery of fosfomycin following extraction was calculated by comparing the fosfomycin mean peak area of QC samples with the values obtained for post-extraction spiked samples, which represented $100 \%$ recovery.

Selectivity was determined by analyzing tissues from 6 healthy pigs, which had never received antimicrobial treatment, each coming from different farms.

\section{$(\boldsymbol{C C} \beta)$}

\section{Decision limit (CCa) and Detection capability}

The decision limit $(\mathrm{CC} \alpha)$ is defined as the limit above which it can be concluded with an error of probability of $\alpha$, that a sample contains the analyte. The detection capability $(\mathrm{CC} \beta)$ is defined as the lowest concentration of analyte at which the method is able to detect and quantify contaminated samples with a statistical certainty of $1-\beta$ (European Commission Decision, 2002).

\section{Matrix effects evaluation}

For matrix effects evaluation, two types of studies were conducted, as described. On one hand, peak area ratios obtained with fosfomycin aqueous solutions, at three concentration levels within the linear range, were compared with those obtained with extracted blank tissues, spiked at the same concentration, just before injection. On the other hand, each blank tissue extract was injected at the same time a fosfomycin aqueous solution was being directly infused into the ion source. Matrix effects were observed by enhancement or reduction of the signal at certain regions of the chromatogram.

\section{Residues analysis and withdrawal time calculation}

\section{Residues analysis}

\section{Oral Assay}

Testing and Sampling: On the fifth day of trial fosfomycin dosage was discontinued. Twenty-four $\mathrm{h}$ later, the first group of animals (six pigs) was sacrificed. The next day, the second group of animals was euthanized (six pigs). After $72 \mathrm{~h}$ of drug dosage suspension, other six pigs were sacrificed. The last group of six animals was euthanized $96 \mathrm{~h}$ after administration.

Samples: Samples were collected in plastic bags (Ziploc $®$ type), quickly cooled and stored at$80^{\circ} \mathrm{C}$ until assayed. A total of 96 tissue samples were obtained (twenty four samples by tissue; six samples by tissue each of the four days of slaughtering). 


\section{TISSUE DISPOSITION AND WITHDRAWAL TIME OF FOSFOMYCIN IN ...}

\section{Intramuscular Assay}

Testing and Sampling: Experimental animals were intramuscularly dosed. Twenty four $h$ after dosage, the first group of animals was sacrificed. The next day, six more pigs were sacrificed. Seventy-two $h$ post-administration, other six animals were slaughtered. The remaining group of six animals was euthanized after $96 \mathrm{~h}$ of intramuscular assay beginning.

Samples: Samples were taken from muscle, liver, kidneys and skin-fat of each animal and they were collected in plastic bags (Ziploc $®$ type), quickly cooled and stored at $-80^{\circ} \mathrm{C}$ until assayed. A total of 96 tissue samples were obtained (twenty four samples by tissue; six samples by tissue each of the four days of slaughtering).

Fosfomycin determination in swine tissues was based on the method previously mentioned. Data processing was performed by Xcalibur software (Thermo Corporation). Quantification was achieved by calculating fosfomycin area as the assay response. The 192 analyzed samples were:

Muscle: Forty eight samples, (twenty-four oral samples and twenty-four intramuscular samples, all analyzed by duplicate).

Liver: Forty-eight samples (twenty-four oral samples and twenty-four intramuscular samples, all analyzed by duplicate).

Kidney: Forty-eight samples (twenty-four oral samples and twenty-four intramuscular samples, all analyzed by duplicate).

Skin-fat: Forty-eight samples (twenty-four oral samples and twenty-four intramuscular samples, all analyzed by duplicate).

\section{Determination of withdrawal times}

The fosfomycin area at each sampling time was considered for the determination of WDTs in muscle, liver, kidney and skin-fat, adopting the European Agency for the Evaluation of Medicinal Products recommendations (EMEA, 1995). The WDTs were estimated from the linear regression analysis of log-transformed tissue concentration and was determined at the time when the $95 \%$ upper one-sided tolerance limit was below the MRL with
95\% confidence. For this purpose, the statistical program WTM 1.4 was used.

\section{Results and Discussion}

\section{Method development}

Optimization of mass spectrometer conditions

High spectrometric response was observed when working in ESI negative ion mode for fosfomycin STD. The predominant ion obtained was de-protonated fosfomycin, which $\mathrm{m} / \mathrm{z}$ value was 137, in the Q1 (or Q3) full scan spectra.

The direct infusion from syringe pump of independent solutions of fosfomycin STD, allowed the observation of changes in response as well as in MS parameters. Thus, the most suitable conditions of the ion source in order to obtain the highest signal from parent ions were found to be the following: Spray voltage: $-3800 \mathrm{eV}$; Spray temperature: $350^{\circ} \mathrm{C}$; Source CID energy: $-8 \mathrm{eV}$ and Sheath gas pressure: 1.5.

Using the same technique, collision pressure and collision energy in Q2 was evaluated. For fosfomycin, a predominant fragment ion of $\mathrm{m} / \mathrm{z} 79$ was formed when collision pressure was 1.6 and collision energy $-25 \mathrm{eV}$. The intensity of parent ions showed a more than $80 \%$ reduction.

\section{Optimization of chromatographic system}

The use of a cyano (CN) stationary phase greatly improved the retention, when compared to a C18.

\section{Method validation}

\section{Validation parameters}

Selectivity

No signal above the base line at fosfomycin retention time was observed in tissues from chickens to which antimicrobials had not been administered. Figures 4 a to 7 a show typical blank chromatograms of muscle, liver, kidney and skinfat, compared with spiked tissue samples (Figures $4 b$ to $7 b)$. 


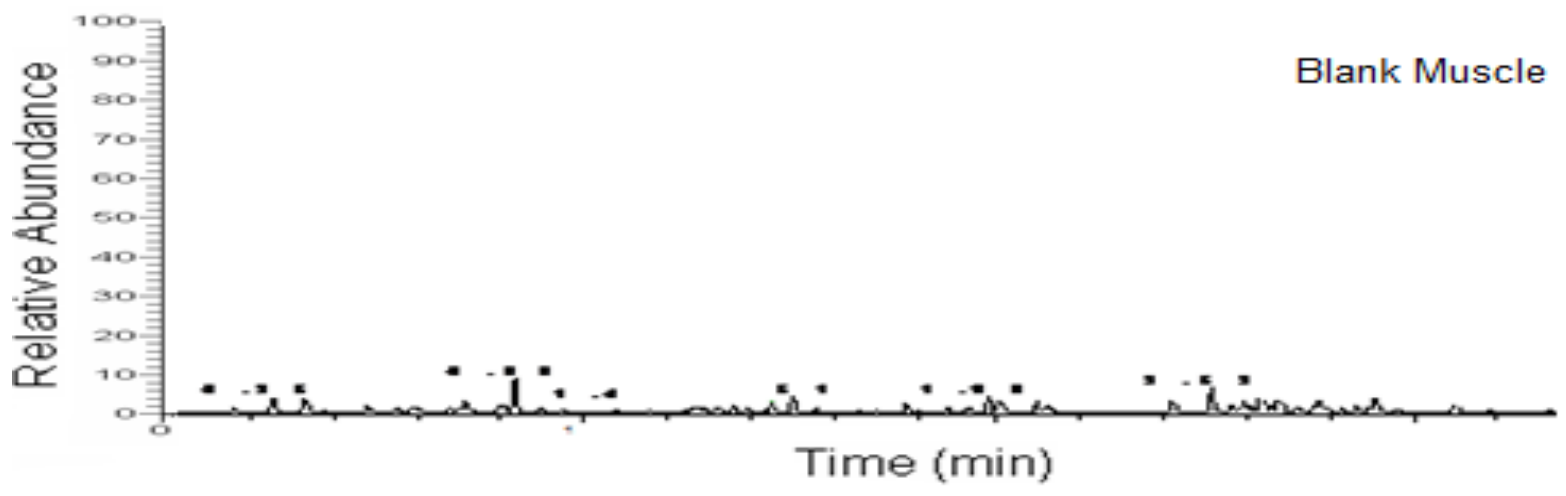

Fig. 4a: Blank muscle.

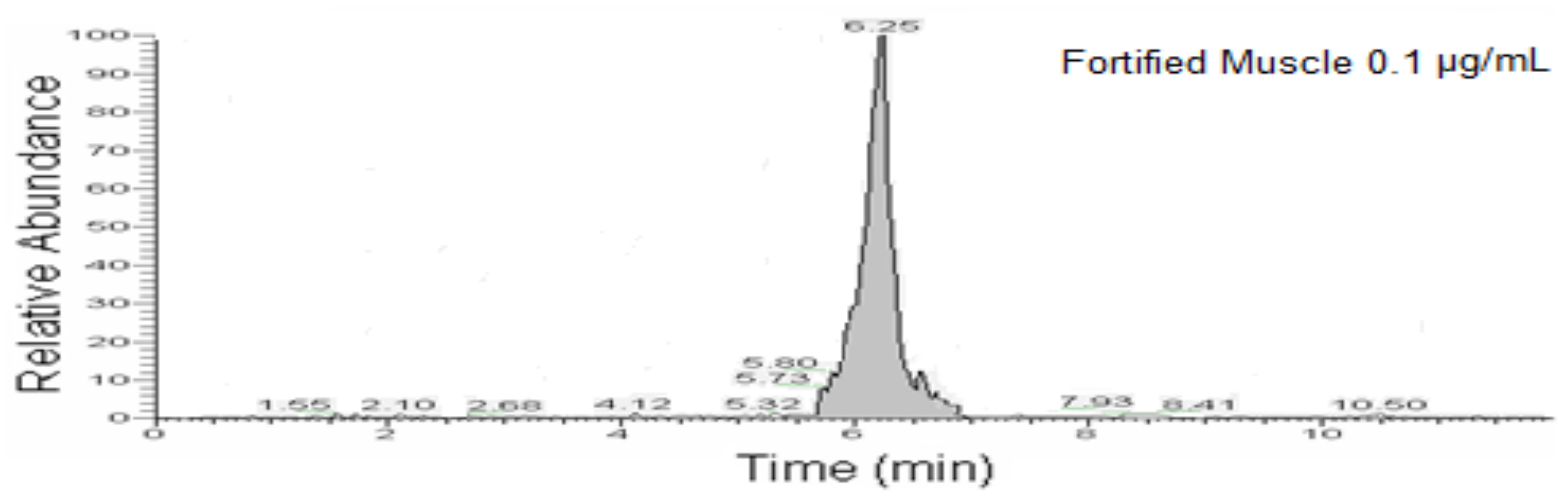

Fig. 4b: $0.1 \mu \mathrm{g} / \mathrm{mL}$ spiked muscle.

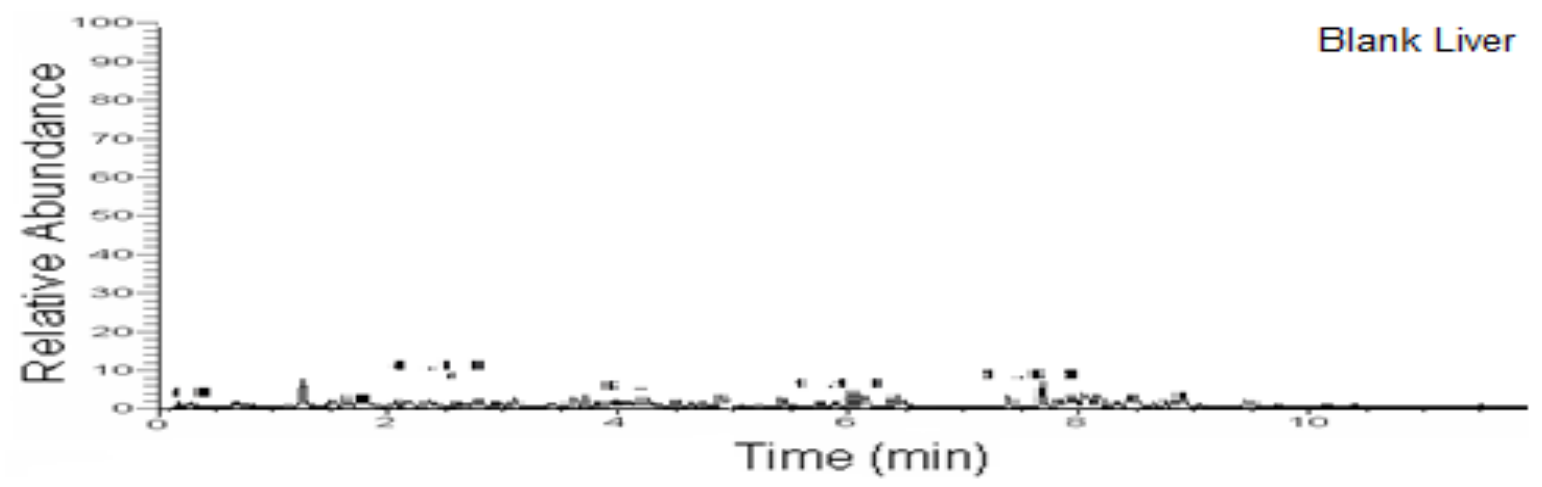

Fig. 5a: Blank liver.

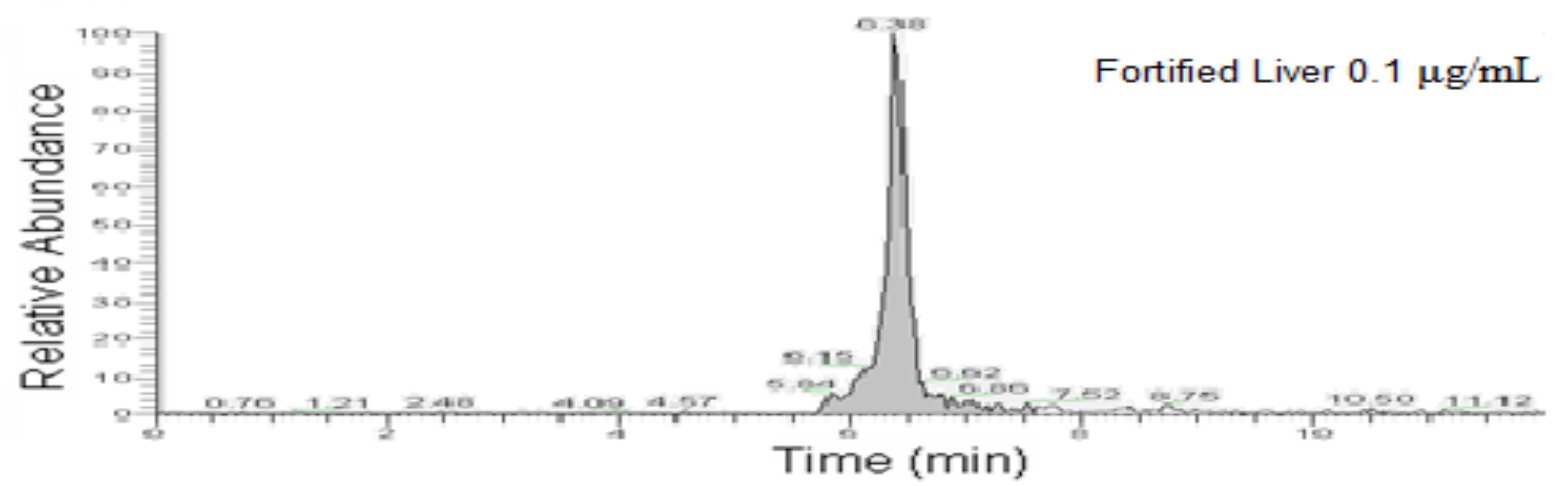

Fig. 5b: $0.1 \mu \mathrm{g} / \mathrm{mL}$ spiked liver. 
TISSUE DISPOSITION AND WITHDRAWAL TIME OF FOSFOMYCIN IN ...

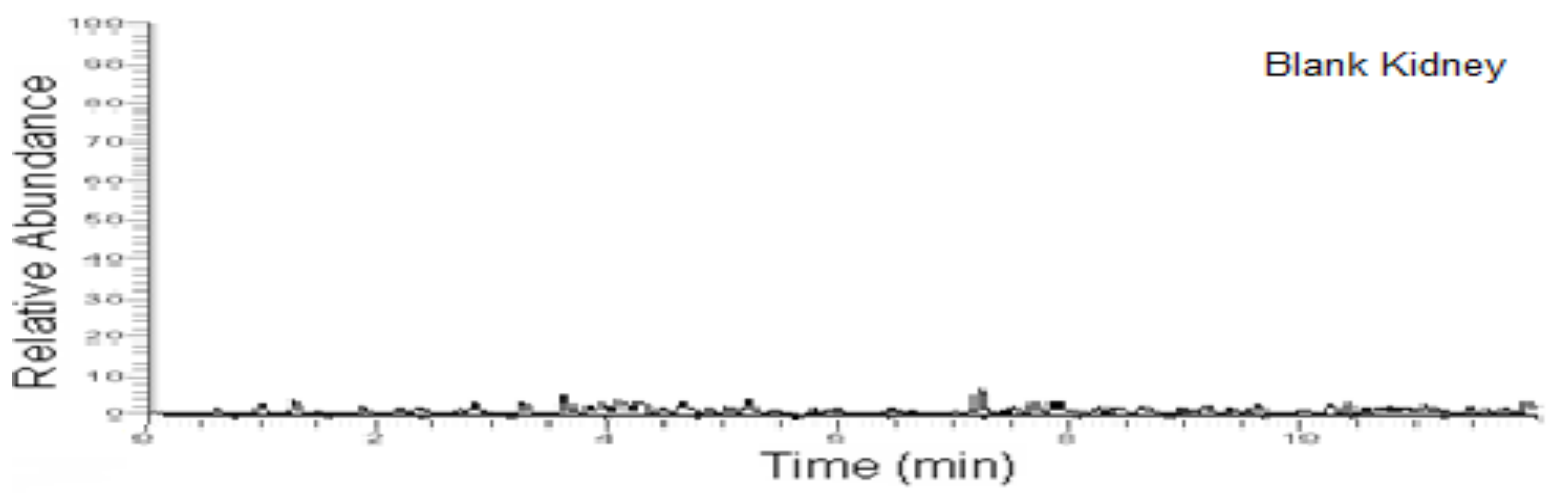

Fig. 6a: Blank kidney.

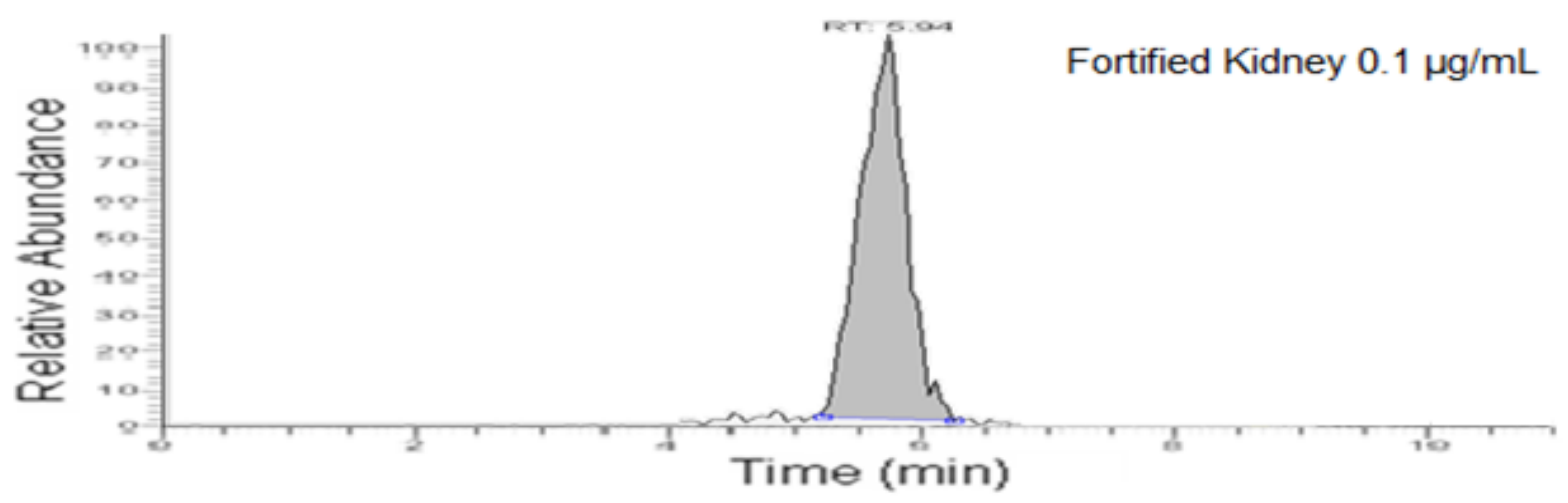

Fig. 6b: $0.1 \mu \mathrm{g} / \mathrm{mL}$ spiked kidney.

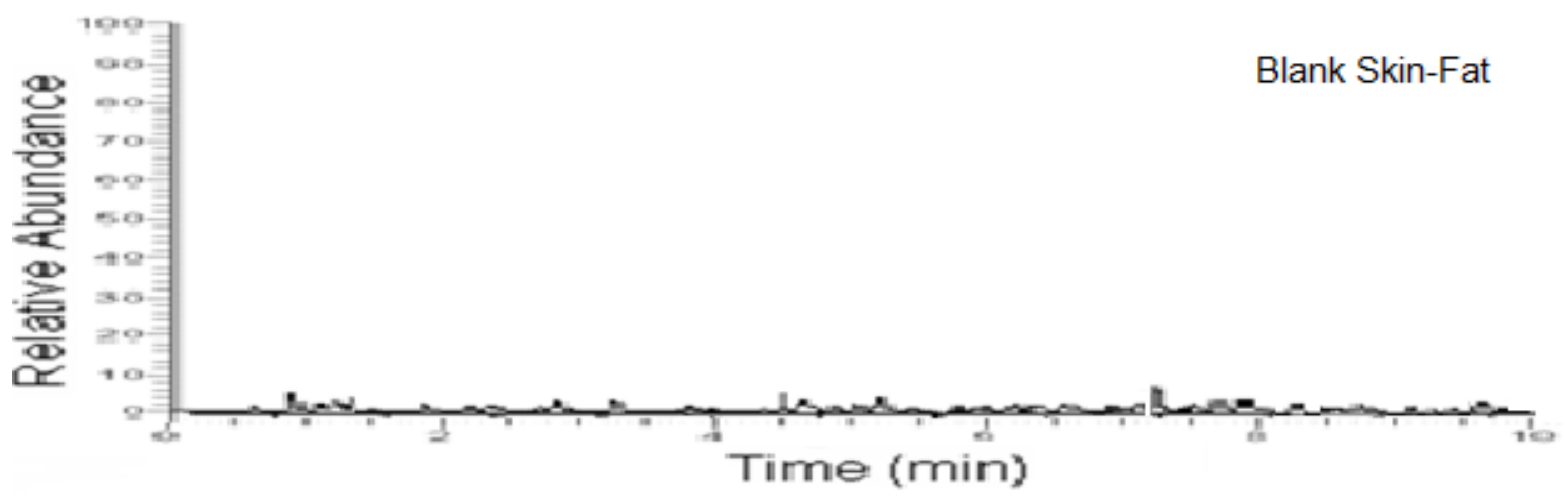

Fig. 7a: Blank skin-fat.

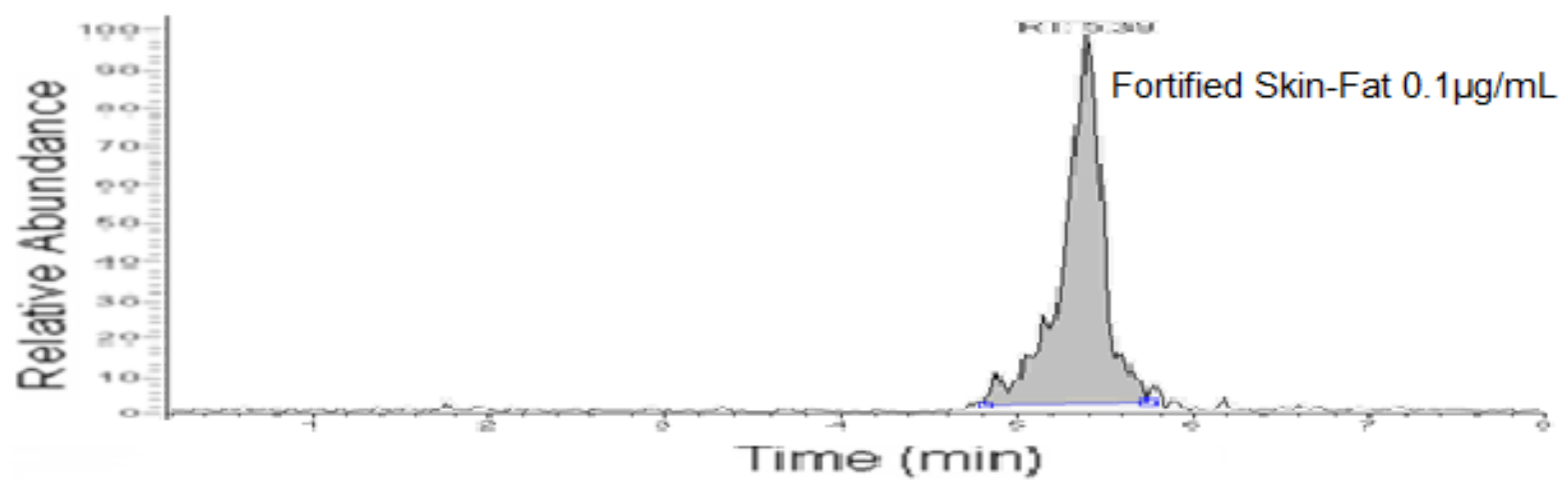

Fig. $7 \mathbf{b}: 0.1 \mu \mathrm{g} / \mathrm{mL}$ spiked skin-fat. 


\section{Linearity}

A typical linear regression curve was constructed over the range 0.01 to $0.4 \mu \mathrm{g} / \mathrm{mL}$ (representing 0.1 to $4 \mu \mathrm{g} / \mathrm{mL}$ of swine muscle, liver, kidney or skin fat). Good linearity was obtained within the concentration range, being $\mathrm{r}^{2}$ coefficient above 0.995 for all matrix replicates.

\section{Accuracy and Precision}

Accuracy and precision were evaluated for spiked samples at different levels. Accuracy, expressed as RE, was $4.00 \%-9.00 \%$ for muscle, $3.00 \%-4.00 \%$ for liver, $2.00 \%-3.00 \%$ for kidney and $2.00 \%-3.00 \%$ for skin-fat. Repeatability (within day precision) was less than $13 \%$ for all studied concentrations, except for the $0.1 \mu \mathrm{g} / \mathrm{mL}$ spiked samples of skin-fat, which was $17.70 \%$, a value that was accepted because it was our detection limit $(\mathrm{CV}<20 \%)$.
Drug recovery was tested for swine tissue samples spiked at different levels. Mean extraction recoveries were between 82.56 to $111.48 \%$ for muscle, 90.85 to $106.93 \%$ for liver, 99.99 to $120 \%$ for kidney and 95.04 to $120 \%$ for skin-fat.

\section{(CCB) \\ Decision limit (CCa) and detection capability}

$\mathrm{CC} \alpha$ and $\mathrm{CC} \beta$ values were calculated using the intercept (value of the signal, $y$, where the concentration, $x$, is equal to zero) and the standard error of the intercept (SEI). $\mathrm{CC} \alpha$ is the concentration corresponding to the intercept + $2.33 \times$ the SEI. CC $\beta$ is the concentration corresponding to the signal at $\mathrm{CC} \alpha+1.64 \times$ the SEI. $\mathrm{CC} \alpha$ was of $0.02 \mu \mathrm{g} / \mathrm{mL}$ for muscle and liver, 0.04 $\mu \mathrm{g} / \mathrm{mL}$ for kidney and $0.05 \mu \mathrm{g} / \mathrm{mL}$ for skin-fat. CC $\beta$ was of $0.04 \mu \mathrm{g} / \mathrm{mL}$ for muscle and liver and 0.08 $\mu \mathrm{g} / \mathrm{mL}$ for kidney and skin-fat.

\section{Extraction Recovery}

Table 1: Summarizes the validation parameters for each matrix.

\begin{tabular}{lccccc}
\hline \multirow{2}{*}{ Parameter } & \multirow{2}{*}{ Accecptance criteria } & \multicolumn{3}{c}{ Tissue } \\
\cline { 3 - 6 } & & Muscle & Liver & Kidney & Skin-fat \\
\hline Lineality $\left(\mathrm{r}^{2}\right)$ & $\geq 0.995$ & 0.999 & 0.997 & 0.997 & 0.998 \\
Precision $(\mathrm{CV} \%)$ & $<15.00$ & $1.02-6.74$ & $0.92-1.05$ & $2.11-2.94$ & $2.15-2.28$ \\
Accuracy $(\mathrm{RE} \%)$ & $<15.00$ & $4.00-9.00$ & $3.00-4.00$ & $2.00-3.00$ & $2.00-3.00$ \\
Recovery $(\mathrm{R} \%)$ & $80.00-120.00$ & $82.56-111.48$ & $90.85-106.10$ & $99.99-120.00$ & $95.04-120$ \\
& & $0,10 \mu \mathrm{g} / \mathrm{mL}$ & $0,10 \mu \mathrm{g} / \mathrm{mL}$ & $0,10 \mu \mathrm{g} / \mathrm{mL}$ & $0,10 \mu \mathrm{g} / \mathrm{mL}$ \\
Limit of quantification & $\mathrm{CV} \%=<20.00$ & $\mathrm{CV} \%=7.62$ & $\mathrm{CV} \%=14.42$ & $\mathrm{CV} \%=6.05$ & $\mathrm{CV} \%=14.75$ \\
& $\mathrm{ER} \%=<20.00$ & $\mathrm{ER} \%=20.00$ & $\mathrm{ER} \%=20.00$ & $\mathrm{ER} \%=20.00$ & $\mathrm{ER} \%=19.00$ \\
$\mathrm{CC} \alpha(\mu \mathrm{g} / \mathrm{mL})$ & - & 0.02 & 0.02 & 0.04 & 0.05 \\
$\mathrm{CC} \beta(\mu \mathrm{g} / \mathrm{mL})$ & - & 0.04 & 0.04 & 0.08 & 0.08 \\
\hline
\end{tabular}

Selection and validation of suitable analytical methods must be previously accomplished in drug tissue depletion studies for determination of WDTs. The HPLC-MS-MS method was selected because of its high specificity and accuracy, which were considered critical factors for this study. HPLC MSMS has been previously used for similar purpose in chicken tissues (Soraci et al., 2011b; Pérez et al., 2011). and studies applying this methodology have been also reported by other authors (Dieguez et al., 2011; Tang and Lai, 2005)

Solid phase dispersion with silica gel was previously used by some authors to determine residual concentrations in biological tissues
(Gutierrez Valencia and García Camacho, 2010; Lei et al., 2005)

The results obtained on the optimization of mass spectrometer conditions and optimization of chromatographic system, were similar to those presented by $\mathrm{Li}$ et al (2007) and Dieguez et al (2011). The use of a cyano (CN) stationary phase markedly improved the retention, when compared to a C18. These optimization parameters, in addition to the good performance that was achieved with water:acetonitrile 80:20 mobile phase, agrees with the results described by (Soraci et al, 2011a; Soraci et al, 2011b; Dieguez et al, 2011; Pérez et al., 2011). 


\section{TISSUE DISPOSITION AND WITHDRAWAL TIME OF FOSFOMYCIN IN ...}

\section{Residues Analysis}

The matrix-matched calibration curves of muscle, liver, kidney and skin-fat were linear ( $\mathrm{r}>$ 0.99) and were used for drug quantification in experimental samples. Tables 2 and 3 show the average concentration $(\mu \mathrm{g} / \mathrm{mL})$ for each tissue after the PO and IM assays, respectively.
Withdrawal time calculation

Estimation of withdrawal time (WDT)

In Table 4, the duration of the WDTs for each assay considering a $0.5 \mu \mathrm{g} / \mathrm{mL}$ MRL are shown.

Table 2: Fosfomycin average concentrations in muscle, liver, kidney and skin-fat. PO assay.

\begin{tabular}{lcccc}
\hline & \multicolumn{4}{c}{ Average concentration $(\boldsymbol{\mu g} / \mathbf{m l})$} \\
\cline { 2 - 5 } & $\mathbf{5 4} \mathbf{~ h}$ & $\mathbf{4 8 ~ h}$ & $\mathbf{7 2 ~} \mathbf{~}$ & $\mathbf{9 6 ~ h}$ \\
\cline { 2 - 5 } & 0.20 & 0.12 & $<0.10$ & $<0.10$ \\
Liver & 2.81 & 0.23 & $<0.10$ & $<0.10$ \\
Kidney & 1.97 & 0.46 & $<0.10$ & $<0.10$ \\
Skin-fat & 0.19 & $<0.10$ & $<0.10$ & $<0.10$ \\
\hline
\end{tabular}

Table 3: Fosfomycin average concentrations in muscle, liver, kidney and skin-fat. IM assay.

\begin{tabular}{lcccc}
\hline & \multicolumn{4}{c}{ Average concentration $(\boldsymbol{\mu g} / \mathbf{m l})$} \\
\cline { 2 - 5 } & $\mathbf{2 4 \mathbf { ~ h }}$ & $\mathbf{4 8 ~ h}$ & $\mathbf{7 2 ~} \mathbf{~ h}$ & $\mathbf{9 6 ~ h}$ \\
\hline Muscle & 0.32 & $<0.10$ & $<0.10$ & $<0.10$ \\
Liver & 0.33 & 0.12 & $<0.10$ & $<0.10$ \\
Kidney & 0.31 & $<0.10$ & $<0.10$ & $<0.10$ \\
Skin-fat & 0.23 & $<0.10$ & $<0.10$ & $<0.10$ \\
\hline
\end{tabular}

Table 4: Fosfomycin withdrawal time in muscle, liver, kidney and skin-fat, after PO and IM administration.

\begin{tabular}{lcccc}
\hline & \multicolumn{4}{c}{ Withdrawal time - MRL 0.5 $\boldsymbol{\mu g} / \mathbf{m l}$} \\
\cline { 2 - 5 } & Muscle & Liver & Kidney & Skin-fat \\
\hline PO assay & 2.78 & 2.69 & 2.95 & 0.90 \\
IM assay & 1.48 & 1.73 & 1.38 & 1.27 \\
\hline
\end{tabular}

On a previous work we have developed and validated the methodology for the determination of fosfomycin residual concentrations in broiler chicken tissues (muscle, liver and kidney). We have also determined the residual concentrations and the WDT of this antibiotic on the mentioned matrices, after both oral and intramuscular administration assays. When compared with our previous work in broiler chickens (Pérez et al, 2011), precision value (CV \%) was higher for pig muscle than for broiler chicken muscle (1.02-6.74 \% vs. 0.42-4.45\%) and lower for liver (0.92-1.05 \% vs. 0.82-4.33\%) and kidney (2.11-2.94 \% vs. 0.23-15.16\%). Accuracy (RE \%) was higher for pig muscle (4.00-9.00 \% vs. 116
$0.49-2.20 \%)$ and kidney (2.00-3.00 vs. 0.30-1.21 $\%)$ and similar for liver (3.00-4.00\% vs. 0.97-3.76 $\%)$. Recovery was similar between the two species for all matrices. For skin-fat all the parameters met the acceptance criteria, and they were not analyzed in our previous work on broiler chickens. The LOQs of $0.1 \mathrm{ppm}$ obtained for all the analyzed matrices were low and accurate enough. They were lower than the only MRL established for fosfomycin residues in animal tissues (0.5 ppm) (Japan Food Chemical Research Foundation) and they are in the same range achieved in broiler chicken tissues. $\mathrm{CC} \boldsymbol{\alpha}$ and $\mathrm{CC} \boldsymbol{\beta}$ were lower but similar to those found in broiler chickens tissues. J. Anim. Prod. Adv., 2013, 3(4):107-119 
Overall, the results of the analytical method validation indicate that the proposed methodology is suitable for the evaluation of fosfomycin tissue residues and for the determination of fosfomycin concentration depletion in swines, in order to establish adequate WDTs.

In this study, fosfomycin tissue concentration and WDTs were determined in pigs after the administration of a daily oral dose $(30 \mathrm{mg} / \mathrm{kg}$ bw for five consecutive days), and after an intramuscular dose $(15 \mathrm{mg} / \mathrm{kg}$ bw $)$ considering the only established MRL for fosfomycin, $0.5 \mu \mathrm{g} / \mathrm{mL}$ (Japan Food Chemical Research Foundation).

There are no previous works which determine fosfomycin tissue concentrations in pigs. Although, there are two works that evaluate the residual concentrations of Fosfomycin in poultry, one of them uses the microbiological assay (Aramayona et al, 2005) and the other uses HPLC MS/MS (Pérez et al, 2011), as we employed for the determination of fosfomycin in pigs.

The administration of oral calcium fosfomycin for five consecutive days at $30 \mathrm{mg} / \mathrm{kg}$ in pigs, showed low residual levels in swine muscle, liver, kidney and skin-fat. In the PO assay, the highest WDT was established for kidney and this is consistent with our previous studies in broiler's tissues (Pérez et al, 2011). Fosfomycin distribution in kidney was higher compared to other tissues (liver, muscle and skin-fat, after oral administration for five consecutive days), probably due to the fact that this organ represents the main route of elimination for the systemically available fosfomycin dose. Even though, kidney concentrations were the highest among the four analyzed matrices after the PO assay, the found values are not so high, and this may be due to the short half-life of the drug and its fast clearance. Moreover, there are not big differences between the WDT established for muscle and kidney, what agrees with our findings in broiler chickens. Such low concentrations are associated with the absence of Fosfomycin tissue protein binding and the poor oral bioavailability of calcium fosfomycin formulation in pigs (F: 20\%) (Pérez et al, 2013).

The intramuscularly administration of disodium fosfomycin at $15 \mathrm{mg} / \mathrm{kg}$ has also showed low residual levels in swine tissues, even lower than those found with the PO administration. In this case, the highest concentrations were found in liver, in contrast to our findings in broilers, were the liver residual concentrations were the lowest after the IM assay. As we have previously reported in broilers (Pérez et al, 2011), Fosfomycin residual concentrations are lower after the IM administration (disodium fosfomycin), than after the PO administration (calcium fosfomycin), and this is due to the high hydrosolubility of the disodium salt.

In all cases, the lowest residual concentrations and the short WDT were those found for skin-fat, owing to fosfomycin high hydrosolubility.

Otherwise, the FDA has established that the edible tissue from which residues deplete most slowly should be considered as the target tissue to evaluate the WDT (Ellis, 2004). According to the EMEA, target tissues for swine's are muscle, liver kidney and skin-fat. For the calculations of WDTs, EMEA (1995) recommends to perform a linear regressions analysis of the logarithmic transformed concentrations during the tissue depletion phase of the drugs and/or their metabolites. Using the model of the EMEA, the WDTs of fosfomycin was determined as the point at which the upper $95 \%$ tolerance limit for the residue is less than MRLs with $95 \%$ confidence. In agreement with the Codex Alimentarius Commission (1995), the lengths of the WDTs are defined by MRLs of each veterinarian drug. In this study, the WDTs of Fosfomycin were determined considering the only MRL defined by Japan. It is worth pointing out that this MRL was established for muscle, liver, kidney and fat from cattle, not for pigs. On this regard, based on the 0.5 $\mu \mathrm{g} / \mathrm{mL}$ MRL of Japan, it is important to note that in both oral and intramuscular assays, concentrations of fosfomycin in muscle, liver, kidney and skin-fat were below the MRL after $48 \mathrm{~h}$ of fosfomycin food withdrawn and of fosfomycin intramuscularly administration. After $72 \mathrm{~h}$, the values of the residual concentrations of the drug in the analyzed tissues were below the $0.1 \mu \mathrm{g} / \mathrm{mL}$ detection limit of our validated method. Fosfomycin WDT in muscle was among 3-2 days, being of 2.78 days for calcium fosfomycin (oral assay) and 1.48 days for disodium salt (IM assay). Differences between fosfomycin muscle WDTs may be due to the distinct formulations and routes of administration. The same 


\section{TISSUE DISPOSITION AND WITHDRAWAL TIME OF FOSFOMYCIN IN ...}

applies to periods of withdrawal in liver and kidney which are also longer after oral calcium fosfomycin consumption in food (2.69 vs. 1.73 days and 2.95 vs. 1.38 days, respectively). Not significant differences were found between the WDTs found for skin-fat after the PO assay (0.9 days) and the IM assay (1.27).

In conclusion, according to our results, it is possible to suggest that a WDT of 3 days for the PO administration, and of 2 days for the IM administration, could be assigned as a precautionary principle for public health, without a significant economic impact for pig producers.

\section{Acknowledgments}

Susana Dieguez and Viviana Menéndez, are acknowledged for their help and work in the method validation.

\section{References}

Aramayona JJ, Bregante MA, Solans C, Rueda S, Fraile LJ, García MA (1997). Pharmacokinetics of fosfomycin in chickens after a single intravenous dose and tissue levels following chronic oral administration. Vet. Res., 28(6):581-588.

Borsa F, Leroy A, Fillastre JP, Godin M, Moulin B (1988). Comparative pharmacokinetics of tromethamine fosfomycin and calcium fosfomycin in young and elderly adults. Antimicrob. Ag. Chem. 32, 938-941

Carramiñana JJ, Rota C, Agustín I, Herrera A (2004). High prevalence of multiple resistance to antibiotics in Salmonella serovars isolated from a poultry slaughterhouse in Spain. Vet Microbiol. 104 (1-2) 133139.

Codex Alimentarius. (1995). Programa Conjunto FAO / OMS sobre normas alimentarias. Residuos de medicamentos veterinarios en los alimentos. 3, 50-93.

Dámaso D, Moreno-López M, Daza RM (1990). Antibióticos y Quimioterápicos Antibacterianos. Uso Clínico. Ed. Marketing Pharm, S.A., Madrid.

Dieguez SN, Soraci AL, Tapia MO, Carciochi RA, Pérez DS, Harkes R, Romano O. (2011). Determination of antibiotic fosfomycin in chicken serum by liquid chromatography-tandem mass spectrometry. J. Liq. Chrom. Rel. Technol. 34, 116-128.

Dios-Viéitez MC, Goñi M, Renedo MJ, Fos D (1996). Determination of fosfomycin in human urine by capillary gas chromatography: Application to clinical pharmacokinetic studies. Chromatogr., 43, 293.

Ellis R (2004). U.S. FDA Regulatory Approach for Control of Residues of Veterinary Drugs. Joint FAO / WHO technical workshop on Residues of Vetrinary Drugs without ADIMRL. Food and Agriculture Organization and World Health Organization, Geneva,

EMEA (1995). (The European Agency for the Evaluation of Medicinal Products). Note for Guidance: Approach towards harmonization of withdrawal periods. EMEA CVMP/036/95, 1-37.

European Commission Decision. Implementing Council Directive Concerning the performance of analytical methods and the interpretation of the results. Off. J. Eur. Comm. L221, 2002/657/EC, 23-33.

Fernández Lastra C, Mariño EL, Dominguez-Gil A. (1987). Phosphomycin levels in serum and interstitial tissue fluid in a multiple dosage regimen in rabbits. Arzneim. Forsch., 37, 927-929.

Gallego A, Rodríguez A, Marín B (1971). Farmacodinamia de la fosfomicina Estudios en animales. An. Inst. Farm. Esp., 20, 397-402.

Gallego A, Rodríguez A, Mata JM (1974). Fosfomycin: pharmacological studies. Drugs Today, 10, 161-168.

Gobernado M (2003). Fosfomicina. Rev. Esp. Quimioter. 16, $15-40$.

Grassi GG (1990). Fosfomycin Trometamol: Historical Background and Clinical Development. Discussion 1: Fosfomycin Trometamol. Preclinical Studies. Infect., 18, 57-59.

Gutiérrez Valencia TM, García Camacho MP (2010). On-line coupling of Matrix Solid Phase Dispersion (MSPD) technique and Liquid Chromatography for the determination of organophosphorus pesticides in biological tissues. ICIAS.

Gutierrez OL (2008). Pharmacokinetics of disodium fosfomycin in mongrel dogs. Res. Vet. Sci. 85, 156-161.

Hernández E, Loste A, Bregante MA, García MA, Solans C (2001). Determination of fosfomycin in chicken plasma samples by gas chromatography: application to pharmacokinetic studies. Chromatogr. 54, 365.

Japan Food Chemical Research Foundation. Table of MRLs for Agricultural Chemicals. Fosfomycin. http://www.ffcr.or.jp/zaidan/ffcrhome.nsf/pages/eng.hpage

Kahan FM, Kahan JS, Cassidy PJ, Kropp H (1974). The mechanism of action of fosfomycin (phosphonomycin). Ann. N. Y. Acad. Sci. 235, 364-386.

Kirby WM. (1977). Pharmacokinetics of fosfomycin. Chemother., 23,141-151.

Lei Z, Yuan L, Meng X, Yue-Ming Q (2005) Simultaneous determination of thyreostatic residues in animal tissues by matrix solid-phase dispersion and gas chromatography-mass spectrometry. J. Chrom. A. 1074, 1-7.

Li L, Chen X, Dai X, Hui Chen XM, Zhong D. (2007). Rapid and selective liquid chormatographic/tandem mass spectrometric method for the determination of fosfomycin in human plasma. J. Chrom. B. 856, 171177.

Lin EC (1976). Glycerol dissimilation and its regulation in bacteria. Annu. Rev. Microbiol. 30, 535-578.

Loste A, Hernández E, Bregante MA, García MA, Solans C 


\section{PÉREZ ET AL.}

(2002) Development and validation of a gas chromatographic method for analysis of fosfomycin in chicken muscle samples. Chromatogr. 56, 3-4.

Falagas ME, Giannopoulou KP, Kokolakis GN, Petros IR. (2008) Fosfomycin: Use beyond urinary tract and gastrointestinal infections. Invited Article. Rev. Anti.infect. Ag. CID, 46:1069-1077.

Martineau GP. (1997). Maladies d'élevage des porcs, manuel practique. Editions France Agricole. Paris.

Mata J, Rodríguez A, Gallego A (1977). Fosfomycin: in vitro activity. Chemother. 23, 23-24.

Mensa J, Gatelí JM, Corachán M, Escofel MC, Martínez JA, Zamora L (1994). Guía de Terapéutica Antimicrobiana. Eds. Científicas y Técnicas, S.A. 4ed. Barcelona,

Patel SS, Balfour JA, Bryson HM (1997). Fosfomycin tromethamine. A review of its antibacterial activity, pharmacokinetic properties and therapeutic efficacy as a single-dose oral treatment for acute uncomplicated lower urinary tract infections. Drugs. 53, 637-656.

Pérez DS, Soraci AL, Dieguez SN, Tapia MO (2011). Determination and withdrawal time of fosfomycin in chicken muscle, liver and kidney. Int. J. Poult. Sci. 10, 644-655.

Pérez DS, Soraci AL, Tapia MO (2013). Pharmacokinetics and bioavailability of calcium fosfomycin in post weaning piglets. Int. J. Agro-Vet. Med. Sci. In press.

Petsch M, Mayer-Helm BX, Sauermann R, Joukhadar C, Kenndler E (2005). Determination of fosfomycin in pus by capillary zone electrophoresis. J. Chrom. A. 1081, 559.

Pianetti GA. (1997) Determinação cromatográfica da Fosfomicina em amostras biológicas. Cad. Farm. 13, 129.

Popovic M, Steinort D, Pillai S, Joukhadar C. (2010) Fosfomycin: an old, new friend? Eur. J. Clin. Microbiol. Infect. Dis. 29, 127-142.

Reeves DS (1994). Fosfomycin Trometamol. J. Antimicrob. Chemother. 34, 853-858.

Segre G, Bianchi E, Cataldi A, Zannini G (1987). Pharmacokinetic profile of fosfomycin trometamol (Monuril). Eur. Urol., 13,56-63.

Simon C, Stille W, Perea EJ (1987). Manual de Terapéutica Antimicrobiana. Salvat Editores, S.A. Barcelona.

Soraci AL, Pérez DS, Martínez G, Dieguez SN, Tapia MO, Amanto F, Harkes R, Romano O (2011a). Disodiumfosfomycin pharmacokinetics and bioavailability in post weaning piglets. Res. Vet. Sci. 90(3), 498-502.

Soraci AL, Pérez DS, Tapia MO, Martínez G, Dieguez SN, Buronfosse-Roque F, Harkes R, Colusi A, Romano O (2011b). Pharmacocinétique et biodisponibilité de fosfomycine chez le poulet de chair. Rev. Méd. Vét. 162, 358-363.

Sumano LH, Ocampo CL, Gutierrez OL (2007). Intravenous and intramuscular pharmacokinetics of a single-daily dose of disodium-fosfomycin in cattle, administered for 3 days. J. Vet. Pharm. Ther. 30, 49.

Tang HP, Ho C, Lai SS (2006). High-troughput screening for multi-class veterinary drug residues in animal muscle using liquid chromatography/ tandem mass spectrometry with on-line solid-phase extraction. Rapid Commun. Mass Spectrom. 20, 2565-2572.

Tzanavaras PD, Themelis DG (2002). Flow-injection spectrophotometric determination of the antibiotic fosfomycin in pharmaceutical products and urine samples after online thermal-induced digestion. Anal Biochem. 304, 244-248.

U. S. Department of Health and Human Services, FDA, CDER, CVM (2001). Guidance for Industry, Bioanalytical Method Validation.

Vargas E, Pacheco E, Beneit JA (1987). Antibióticos (V): Misceláneos: Fosfomicina. In: Farmacología y su proyección a la clínica. Velázquez, B. L. Ed. Oteo. Madrid., 840-841.

Yu-Ling H, Yu-Qi F, Ping-He Z, Shi-Lu D (1999). Determination of fosfomycin by indirect spectrophotometric method. Talanta. 49-47.

Zozaya DH, Gutiérrez OL, Ocampo CL, Sumano LH. Pharmacokinetics of a single bolus intravenous, intramuscular and subcutaneous dose of disodium fosfomicina in horses. J. Vet. Pharm. Ther. 31, 321-327. 